\title{
Das andere Kino
}

Erhard Taverna
Der SED-Staat ist untergegangen, doch seine Lebensart wirkt nach und wird es noch lange tun. Zurzeit bietet sich in Deutschland, und hoffentlich bald auch bei uns, eine hervorragende Gelegenheit, das Filmschaffen einer untergegangenen Gesellschaft kennenzulernen. Viele Probleme der neuen Bundesländer, die oft für Schlagzeilen sorgen, werden besser verständlich, und zudem sind überraschende Entdeckungen zu machen, die einst dem kalten Krieg zum Opfer fielen.

\section{Das Projekt des Modern Museum of Art (MoMa)}

Nach fünfjähriger Vorbereitung hat das renommierte Museum in New York, in Zusammenarbeit mit dem Goethe-Institut, eine Werkschau mit 20 Filmen der DDR herausgebracht. In Anlehnung an den bekannten James-Dean-Film bekam der Zyklus den Titel «Rebels with a cause, the Cinema of East Germany». Nachdem die Filmreihe in mehreren Grossstädten der USA gezeigt wurde, läuft das Programm in acht deutschen Städten. Damit wurde die längst fällige Würdigung einer Produktion möglich, deren Meisterleistungen der westlichen Konkurrenz in jeder Hinsicht ebenbürtig sind.

Im Mai 1945 übergab ein sowjetischer Kulturoffizier in Babelsberg die Gründungsurkunde für eine neue Filmfirma, die «Deutsche Film AG», kurz DEFA genannt, deren Anteile 1949 vollständig an die DDR übergingen. Die Studios produzierten von 1946-1990 und beschäftigten über 3000 Künstler, Techniker, Handwerker und Angestellte. Unter wechselnden, aber stets schwierigen politischen und ökonomischen Bedingungen wurden rund 700 Spielfilme, davon 160 für Kinder und etwa weitere 550 Filme für das Fernsehen, gedreht. $\mathrm{Zu}$ den letzten Amtshandlungen des alten Regimes gehörte die gesetzliche Vorbereitung einer Stiftung, die 1998 von der Bundesrepublik realisiert wurde. Zweck dieser Stiftung ist die Erhaltung des umgangreichen Materials, dessen Bekanntmachung einer breiten Öffentlichkeit und die aktive Förderung des Filmschaffens. Der «Progress Filmverleih» bekam dafür die weltweit exklusiven Aufführungsrechte und ist mit zusätzlichen 5000 Dokumentarfilmen, Wochenschauen und Periodika aus jener Zeit der grösste Repertoirefilmverleih. 15 von 100 Werken, die von der deutschen Kine- mathek als bedeutendste Beiträge aufgelistet sind, stammen aus dieser Quelle. Einen wichtigen Beitrag gegen das Vergessen leistet auch die international tätige Video- und DVD-Firma «Icestorm», die mit DEFA-Märchen- und Indianerfilmen grosse Verkaufserfolge erzielte.

Jedes Jahrzehnt brachte für Schauspieler und Regisseure neue Schlupflöcher und Hindernisse. In der Ulbricht-Aera war die Zensur stalinistischrepressiv. Filme wie «Berlin Ecke Schönhauser» (Gerhard Klein 1957) wurden mit Abstrichen

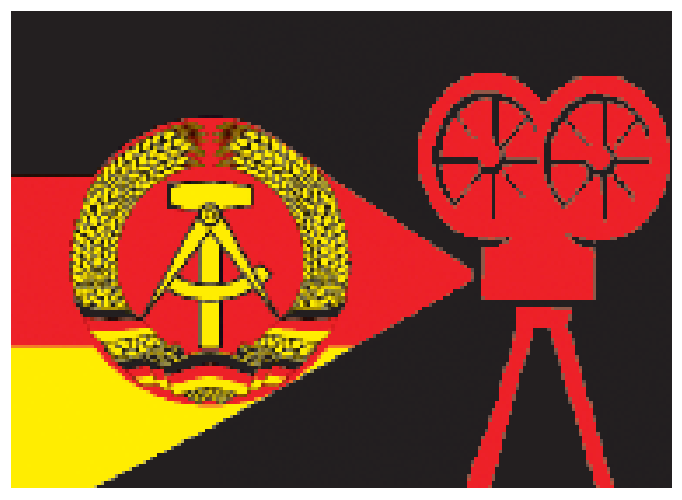

gezeigt, andere wie «Jahrgang 1945» (Jürgen Böttchner 1966) verschwanden ohne Aufführung im Regal. 1965 wurde ein ganzes Programmjahr verboten. Die erwähnten Filme sind nicht nur wertvolle Zeitdokumente, sie sind, wie alle anderen auch, Lehrstücke über ein Zensursystem. Populäre Filme wie «Der Dritte» (Egon Günther 1972) oder «Die Legende von Paul und Paula» (Heiner Carow 1973) vermitteln ein realistisches Lebensbild eines weitgehend isolierten Landes. Die Dialoge sind intelligent und witzig, selten agitatorisch; Stars wie Angelica Domröse und Jutta Hoffmann hätten auch bei uns eine grosse Karriere gemacht. Publikum und Hersteller verstehen es, zwischen den Zeilen zu lesen, denn Repression macht erfinderisch und hellhörig. Nach einer kurzen Tauwetterperiode begann mit Honeckers Verurteilung eine neue Eiszeit: «Unsere DDR ist ein sauberer Staat. In ihm gibt es unverrückbare Massstäbe der Ethik und Moral, für Anstand und gute Sitte. In einigen während der letzten Monate bei der DEFA produzierten Filme zeigen sich dem Sozialismus fremde, schädliche Tendenzen und Auffassungen.» Ganz anders ist wiederum ein Film aus der Endzeit wie «Die Architekten»(Peter Kahane 
1990), der unverblümt und pessimistisch eine Gesellschaft in voller Auflösung zeigt. Die staatlichen Spielverderber haben ausgespielt, was bleibt, ist eine Talentschau, eine späte Rehabilitierung, ein Archiv mit unterhaltenden und lehrreichen Einblicken in eine uns damals weitgehend verschlossene Welt.

In diesem Zusammenhang ist noch auf ein weiteres Filmprojekt hinzuweisen, das nicht dem Zyklus angehört, aber in seiner Art wohl einmalig ist: «Die Kinder von Golzow», eine unendliche Geschichte von 1961 bis 2005, 33 Stunden Lebensläufe auf 400 Kilometern Filmmaterial. Barbara und Winfried Junge haben lebensläng- liche Porträts aus einem Dorf im Oderbruch, nahe der polnischen Grenze, nachgezeichnet. Vom Sandkasten zur Schule bis zur Wende und danach. Privates wird öffentlich, ehemalige Liebhaber, vergangene Weltbilder, Illusionen, unerfüllte Träume, Niederlagen und Gewinne, Kämpfe und Kompromisse. Aus dem Projekt, «die Anfänge und den Werdegang des Sozialismus» zu studieren, entstand ein Laborlangzeitdokument über ein gesellschaftspolitisches Experiment. Ein ergreifendes und berührendes Biographiemonument, unvergleichlich und dennoch allgemeingültig. Auch davon, ist zu hoffen, werden Ausschnitte in unsere Kinosäle gelangen. 